\title{
The Group Values of Educational Encounters: Working with Service Users and Students in a Participatory Classroom Environment
}

\section{Gloria Kirwan}

To cite this article: Gloria Kirwan (2013) The Group Values of Educational Encounters: Working with Service Users and Students in a Participatory Classroom Environment, Social Work With Groups, 36:2-3, 191-207, DOI: 10.1080/01609513.2012.753840

To link to this article: https://doi.org/10.1080/01609513.2012.753840

曲 Published online: 28 Mar 2013.

Submit your article to this journal $₫$

Џلll Article views: 257

Citing articles: 2 View citing articles ๘ 


\title{
The Group Values of Educational Encounters: Working with Service Users and Students in a Participatory Classroom Environment
}

\author{
GLORIA KIRWAN \\ School of Social Work and Social Policy, Trinity College, Dublin, Ireland
}

This article examines a participatory educational group approach to involving service users in a social work education programme. In particular it focuses on the skills and values that informed the lecturer's management of this group process and the relevance of the International Association for Social Work with Groups Standards for Social Work Practice with Groups to the purpose of the group as well as to how this group was facilitated.

KEYWORDS classroom-based group, mental health service user perspectives, experts by experience, participatory education, service users as educators, IASWG and AASWG Standards

The research-aware and capable practitioner should be confident in making connections between the work done with service users and the wider community. (Adams, Dominelli, \& Payne, 2005, p. 298)

\section{INTRODUCTION}

The wider literature records benefits of involving service users in the education of students in professional educational programs including social work degrees (Elliott et al., 2005; Forrest, Risk, Masters, \& Brown, 2000; Gee \& McPhail, 2010; Kjellberg \& French, 2011; Tickle \& Davison, 2008). To date, the literature on the involvement of service users in classroom-based learning has tended to focus on the pedagogical content of such initiatives. In contrast, the literature has devoted minimal attention to the group dynamics

Received: February 2, 2012; Revised July 12, 2012; Accepted: October 13, 2012.

Address correspondence to Gloria Kirwan, School of Social Work and Social Policy, Trinity College Dublin, Arts Building, Dublin 2, Ireland. E-mail: kirwangm@tcd.ie 
involved in bringing together service users and students in a classroom setting.

This article aims to raise awareness and possibly debate about the group facilitation knowledge and skills required of educators involved in the organization of student and service user classroom-based encounters. Specifically, it explores the importance for educators of attending to the group processes and dynamics surrounding this level and intensity of engagement between students and service users. As a point of reference, this article charts the story of a service user/student educational group experience and considers the values, knowledge and skills used by the lecturer in the "group facilitator" role. As is illustrated, the Standards for Social Work Practice with Groups (Association for the Advancement of Social Work with Groups [AASWG], 2010) became an important point of reference in guiding that facilitation. The Global Standards for the Education and Training of the Social Work Profession (International Association of Schools of Social Work and International Federation of Social Workers [IASSW/IFSW], 2004) also informed this curricular initiative.

\section{BACKGROUND}

The development of the social work curriculum is an ongoing and fluid process. In recent times, the need to include curriculum content elucidating "service user" perspectives" has become a common educator mantra across professional social work degree programs. The educational group discussed in this article arose from the author's attempt to create a learning environment where meaningful exchange and dialogue could take place between student social workers and mental health service users.

This innovative approach involved two service users attending every class of a particular module and auditing the teaching content. What started as a simple exercise, designed to bring students and service users together, developed into a collaboration involving the service users, students, and lecturer in a challenging but highly informative educational experience. For the students, who had signed up for a module titled Social Work and Mental Health, the journey through the module involved them directly in a real group encounter-something initially unplanned and unexpected in the context of the module and something that is inherently difficult to achieve in a classroom setting.

In the sections that follow, this article includes consideration of the service user as an expert by experience ${ }^{2}$ (Beresford, 2007; Beresford \& Evans, 1999; Preston-Shoot, 2007) and the benefits that can flow from including the service user perspective in social work education. It also considers how relevant and useful the Standards (AASWG, 2005) were in terms of guiding and informing the development and facilitation of this educational group encounter. 


\section{SERVICE USERS: EXPERTS BY EXPERIENCE}

The push to recognize the unique contribution that service users can make to the evaluation and planning of the services they use has predominantly emerged from global service user movements that have sought to deconstruct and redefine societal responses to issues such as disability, mental health, and youth (see, e.g., Crossley, 2006; Oliver, 1990). In this context, mental health service users have campaigned for recognition of their right to be heard and consulted as receivers, users, and consumers of mental health services.

With reference to the history of such social movements in the United Kingdom, Warren (2007) traced the evolution of the Disabled People's Movement, the Adult Carers' Movement, and the Mental Health System Survivor's Movement in terms of how each has emerged since the 1960s. Across these three fields a proliferation of service user representative organizations, support services, and service user-led research has developed. All of these activities have contributed to awareness raising and an emphasis on the need to listen to understand, and engage with the viewpoints and experiences of service users.

"Respect for persons and their autonomy" is a foundational principle and core value within the Standards (AASWG, 2010, p. 4) and reflects the proximity of social work values to the issues that service user movements seek to raise. The Standards state that "a major implication of this principle is a respect for and a high value placed on diversity in all its dimensions such as culture, ethnicity, gender, sexual orientation, physical and mental abilities, and age" (AASWG, 2010, p. 4).

An overall aim of the educational group described in this article was to raise student awareness of the importance of respecting diversity in society and of actively engaging with people who find themselves in disempowered positions within society. This is also directly linked to the second core value of the Standards (AASWG, 2010) that is "the creation of a socially just society" (p. 4). It is important that social work students understand the lived realities of those whose lives involve experiences of stigma, discrimination, and disadvantage. It is also relevant for student social workers to gain opportunities that help them understand that social change is not only effected at the macrolevel of practice but can also be something they achieve through the nature of their daily interactions with service users and their families.

\section{THE SERVICE USER PERSPECTIVE IN SOCIAL WORK EDUCATION}

Apart from the growth in various service user-led social movements, there are a number of additional factors contributing to the growing focus in social work education on service user perspectives. For example, the benefits that 
derive from incorporating service user feedback into service agency performance measures, particularly in the field of adult mental health, have been reflected in the policy and research literature (Chamberlin, 2005; Department of Health and Children [DoHC], 2006, 2008; Lasalvia \& Ruggeri, 2007); although Braye (2000) reminded us of the gulf that sometimes exists between the rhetoric and reality of service user-informed service planning.

Writing about consultation with young people, Farrell (2010) captured quite succinctly the essence of why social workers benefit from listening carefully to the views of service users regarding the quality and adequacy of the services they receive:

\begin{abstract}
Social Work [with young people] would benefit from being more centrally informed by the views and experiences of service users because, by being more informed, it can become more responsive to their needs. . . . By being more centrally informed by the views and experiences of young people, social work can work towards empowering these young people and allowing them to gain more control over their lives. (pp. 20-21)
\end{abstract}

Farrell (2010) added that in traditional social work relationships, social workers provide and service users receive, thus placing the social worker in a position of power. Relinquishing this powerful position requires social workers to engage in a different way with service users and to recognize the validity of their views and their experiences.

Another factor drawing curriculum attention to service user views is related to the ongoing internal debate within the social work profession about the need to build alliances with service users so that the rhetoric of empowerment and equality can translate into real change. An expression of how the profession is responding to this internal debate is found in the Global Standards (IASSW/IFSW, 2004), a statement that was adopted by the General Assemblies of the International Federation of Social Workers and the International Association of Schools of Social Work in Adelaide, Australia, in 2004. The standards outlined in the IASSW/IFSW document promote the adoption by social work educators of a key set of concepts that can inform curriculum design and content. These include a commitment to reflect "the values and ethical principles of social work," as well as respect for: "the rights and interests of service users and their participation in all aspects of the delivery of programmes" (IASSW/IFSW, 2004, p. 4).

To this end, IASSW/IFSW (2004) enunciated core subjects for inclusion on the social work curriculum including "knowledge about and respect for the rights of service users" (p. 8).

These standards have led social work education programs across the world to include awareness-raising inputs regarding service user views and perspectives. In the United Kingdom, the issue has moved a step further, and there the involvement of service users is now a mandated feature of social 
work education (Department of Health [DoH], 2002). As a consequence, service users now regularly participate in the design, delivery, and evaluation of the social work curriculum and also sometimes in student selection and assessment. This form of mandate has raised the focus on finding ways to achieve greater service user involvement in social work education. Duffy (2006, 2008) and Agnew and Duffy (2010) reported on a range of initiatives undertaken within the United Kingdom that have succeeded in breaking new ground in the area of service user involvement in the education of social work students. Mandated service user involvement in social work education is not in place in the jurisdiction where this author is presently located (Republic of Ireland), but the spirit of inclusivity regarding the participation of service users in social work education is nonetheless reflected in the guidance on social work qualification program procedures that is issued to social work educators from the social work regulatory agency ([CORU], 2011, p. 23).

A further issue that is highlighted by the IASSW/IFSW (2004) document is the importance of developing student skills in cultural competence and inclusive practice. It indicates that social work educators should seek to ensure that

social work students are provided with opportunities to develop selfawareness regarding their personal and cultural values, beliefs, traditions and biases and how these might influence the ability to develop relationships with people and to work with diverse population groups. (p. 11)

This emphasis on inclusivity and respect for difference is an example of the growing commitment within the wider social work profession to engaging with and valuing the views and wishes of service users and is reflective of a move away from the "professional as expert" identity to the "professional as partner."

These shifts have implications for the future directions and development of the social work profession. In the context of mental health social work, for example, Wilson and Kirwan (2007) concluded that its future identity as either an agent of care or of control is inextricably linked to the position it adopts vis-à-vis the mental health service user movement, a movement with increasing sociopolitical influence (see also Wilson \& Daly, 2007).

Jackson's (2005) study of service user involvement and how it links with social work practice concludes that if user involvement is to be actualized in social work, then social workers will have to take conscious steps to help break down the barriers that currently exist in relation to such involvement. For Jackson (2005), one possible remedy is to better utilize service user knowledge as a teaching resource and to find ways of placing the service user experience at "the heart of knowledge" (p. 41) in social work education. 
In agreement with Jackson (2005), and based on the educational group experience reported here, it is argued that the social work classroom provides a natural environment in which many barriers to inclusion and mutual understanding between social workers and service users can be explored and broken down. An opportunity exists for social work educators to use the group context of social work education (i.e., the class or group of students who study any given module together), to encourage students to become what Smith (1995) terms "critical enquirers" and explore their understandings and possible biases towards minority groups and other groups of service users.

The next section recounts the story of the educational group experience that brought service user perspectives to a central position within a mental health social work module. The group facilitation skills involved in supporting student and service user contact over the course of that initiative are outlined in detail.

\section{THE SERVICE USER AUDIT AS AN EDUCATIONAL GROUP EXPERIENCE}

From the earliest discussions concerning the involvement of service users in the Social Work and Mental Health module, the lecturer (author) and a service user representative organization sought to find an effective method of teaching students to appreciate the contribution that service users can make to societal understandings of mental health service provision. All parties were anxious to avoid the tradition in some educational programs whereby service users are timetabled to give stand-alone inputs to students. In many instances, these onetime only or occasional presentations translate into tokenistic gestures of service user involvement in education (Cuming \& Wilkins, 2000) but have little impact on changing students' views.

The idea of putting into practice a real-life example of social worker/service user collaboration grew during the premodule negotiations and out of this dialogue a novel approach to service user involvement in the curriculum took shape. The final plan that emerged was for the lecturer to break through her own rhetoric of service user involvement by subjecting her work, that is, module design and teaching input, to a service user-led audit.

Organizing a teaching module along these lines represented a powerful statement in and of itself attaching as it did value to service user knowledge and expertise. It also displayed to the students how the service users and lecturer could work together on equal terms in a mutually respectful and empowering way. The Standards states that "the worker should be mindful of the quest for a society that is just and democratically organised. . . This value is presented to the group whenever this is appropriate 
and reinforced when members articulate it" (AASWG, 2010, p. 5). In developing the planned involvement of service users as auditors of the lecturer's work, a clear message was delivered that service users could offer a valid and valuable contribution within the social work curriculum in general and within this specific subject area in particular. It also provided a mechanism to engage stakeholder input from the planning stages of the module onwards. This corresponds with the IASWG Standards regarding the collaborative development of the beginning contract of a group (AASWG, 2010, p. 15).

The issue of power in the classroom setting also entered into the planning for this group. Guided by principles of empowerment and equality, the audit, as it was planned, set out to break down any power imbalance between the lecturer and the service users. By acknowledging the expertby-experience role of the service users, whose stated task was to audit the work of the lecturer, this modeled for students a more equal and mutually respectful relationship between the lecturer and service users. It also created a real-life event in which the lecturer sought service user feedback with the intention of using that feedback to shape future module design. This approach explicitly and deliberately set out to deconstruct what Doel and Sawdon (1995) refered to as the "sapiential authority" (p. 197) of the lecturer and in its place to recognize and privilege the value of the service user's status as experts by experience.

The Standards (AASWG, 2010) outlines the need for group facilitators to understand the nature of the helping relationships that operate within a group:

that the group consists of multiple helping relationships ... [and is a place where] each member's contribution to the group is solicited and valued. ... Group process and structures encompass all transactions that occur within the group .... and also determine whether and how the group will accomplish its purposes. (pp. 7-8)

The design of this module raised the profile of the meaningful contribution service users can make. In addition, how the group was facilitated, it is argued, contributed significantly to the overall achievement of the group's purpose. Involving service users in classroom settings, wherein their input is valued and their expertise properly utilized, serves to raise awareness of the potential contribution service users can make to professional education.

O'Dee (1995) made the point that part of the social work task is to "challenge injustice, seek policy change where appropriate, mobilise people to take control of their lives where possible, help them identify and pursue their rights and help them to gain access to resources" (p. 175). To work at this level, she believed, requires social workers to utilize critical reflection, and she highlighted the opportunities that group discussions provide for social workers to reflect on the values that influence and inform their 
practice. In the context of this educational group encounter, the opportunity for students to widen their knowledge of mental health services and how service users experience them took place in a group environment where service users were present. By creating this educational group setting, utilizing ideas of empowerment (AASWG, 2010, p. 7), all players could engage on equal terms with each other through critical inquiry and knowledge exchange.

\section{FACILITATION SKILLS AND KNOWLEDGE}

This section discusses key issues regarding the group planning and facilitation and highlights specific sections of the Standards (AASWG, 2010) that guided and shaped these activities.

\section{Pregroup Phase}

As outlined in previous sections, the conceptual and pedagogical justifications for the planned collaboration between the lecturer and service user representatives were clearly defined and articulated in advance of the commencement of the delivery of the module to students.

The class comprised approximately 20 social work students. Already as part of their degree, this student cohort had social work placement experience and in addition was accustomed to interactive methods of teaching and learning. However, the presence of two service users in the classroom for an entire module was not something they had ever encountered as part of their academic program. Nor had the lecturer!

As the commencement date of the module began to approach, a sharper focus came into play in relation to the actual facilitation that would surround the introduction of the service users to the students and their participation in every class lecture. The Standards (AASWG, 2010) outlines the skills and knowledge, including planning skills, required of group workers, "a clear understanding of the stages of group development and the related group character, members' behaviours and task, and worker tasks and skills that are specific to each stage" (p. 8). In advance of the group, considerable effort was deployed in planning and structuring aspects of the group to create a safe and stimulating learning environment. Also, a feedback mechanism for the service users' observations on the module content and delivery was developed. In addition, it was decided through consultation that the service users would introduce themselves to the students and that they would thereafter sit in on the lectures and observe the full delivery of the module. As part of this arrangement, it was initially agreed that the service users would offer any contributions they wished and that they would do this after the lecture content had been delivered. 
As the starting date approached, the lecturer's attention was drawn to additional "process" as well as "procedural" issues, many of which are highlighted in the Standards (AASWG, 2010, pp. 11-12). How best to manage the 20:2 ratio or was it really 20:2:1 ratio if the lecturer was also categorized as a participant in this unchartered journey? As planning for the first session proceeded, the lecturer began to return more often to her group facilitation knowledge and the Standards (AASWG, 2010). Issues that required consideration included how to establish the group as a safe place, modeling prosocial behavior and respect for all participants as well as norm setting. It became clear to the lecturer that these were issues related to the experiential element of the initiative that needed to be actively managed and facilitated if the potential success of the group experience was to be unlocked.

In particular, a set of key issues emerged requiring attention from the lecturer in facilitating the introduction of the service users to the students and vice versa. Firstly, the principle of working in partnership with others needed to remain a primary influence on every aspect of the initiative. The module in its style of delivery would depart from the traditional didactic style because two service users would be present in the auditor role. But did the lecturer have the right to impose such a different learning structure on this group of students? Equally, would it be respectful to bring two service users unannounced into the classroom and simply expect business as usual from the students? Clearly, a process of consultation in advance of the entry of the service users into the classroom would need to take place. This consultation with the students would have to be meaningful, but also the service users would need to be aware that it was being done, and that their involvement in the module was contingent on agreement from the students for this plan to proceed.

Le Riche and Taylor (2008) described partnership approaches in social work education (be they partnerships with students, service users, or carers) as "marked by respect for one another, role divisions, rights to information, accountability, competence, and value accorded to individual input" (p. 12). By sharing with the students details of the plan for the module during an induction session at the start of the semester, and consulting them on their views and feelings regarding this plan, patterns of negotiation, and consensus building were introduced in the early formative stages of this group. As part of that initial consultation between the lecturer and the students, they were asked to further discuss the proposal for the initiative without the lecturer present and to convey any concerns via the student class representatives. No objections to the plan were raised by the students.

\section{Confidentiality}

The second issue that arose related to confidentiality, an issue highlighted in the Standards (AASWG, 2010, p. 13). For example, consideration was 
devoted to the following questions: How much personal information sharing would be appropriate between the students and service users? Should service users be introduced? Should students be introduced? What level of information would each set of participants need to know about the other? It was also possible if not probable that there were many things about both sets of participants that $\mathrm{I}$, in the lecturer role, did not know. How then could I go about supporting meaningful information sharing while preserving appropriate boundaries within the group?

Also, the boundary around the group required attention and consideration afforded to the confidentiality of everyone. The Standards (AASWG, 2010) states clearly that facilitators must address issues related to group functioning including rules of group conduct and behavior between members, "'Contracting procedures, including the identification and clarification of group purpose and behavioural standards and norms needed to actualize group goals as determined by potential members, the worker, and the agency" (p. 14). This issue of confidentiality required further consultation with the students and the service users in advance of their first meeting. Such consultation provided an opportunity to clarify how much information each set of participants was willing to share with the other in their first classroom encounter (or throughout the life of the group). Again, these actions provided a real-life experience for the students of how issues such as these can be tackled within a group.

\section{Shaping Norms of Group Participation}

At the first meeting (class lecture), where all parties were present in the room, the larger set of participants (the students) was invited to introduce themselves first and then the smaller group (two service users) gave a brief outline of their personal histories, their role in the service user organization they represented, and also their reasons for being interested to act as module auditors. This time spent listening and sharing established a norm of information exchange that permeated all meetings (classes) of the group that occurred thereafter.

A further factor that influenced the performance of the group was how the lecturer introduced the aims of the audit and explained what would be expected of each set of participants within the classroom interactions. An early concern for the lecturer was that students would stop attending or resist engaging in class discussion, if they could not safely anticipate how the class would be structured. Again, with the benefit of prior consultation, it was agreed that the classes would be conducted as normal, that I would provide teaching input followed by class discussion, with the service users in a mainly observational role for most sessions but possibly leading one of the classes toward the end of the full module. 
The importance of reviewing and monitoring the progress of a group is an issue highlighted clearly in the Standards (AASWG, 2010, p. 14). With this purpose in mind, it was agreed that the service users would provide me with verbal or written feedback directly after each session, and that the feedback would mainly address my teaching style or delivery, as well as teaching content, but would not be about student input or any student-related issue. This debriefing arrangement also provided an opportunity for me to check in with the service users after each session about how they had experienced the class. Conscious that I was not only facilitating, but also actively teaching during the group sessions, this regular checking-in exercise offered me the opportunity to become aware of any issues requiring attention on my part.

\section{Evaluation}

At the midway point of the module written feedback was gathered from the students to ascertain how they were individually responding to the module content and style of delivery. An end-of-module evaluation was also conducted to seek feedback about the overall module from students and service users. The debriefing exercise involving the lecturer and the service users after each class also provided valuable insight into the content and process of each session.

\section{Power of Group Process}

Having put considerable time and effort into preparing all the participants for the start of the module all that remained was for the lecturer to deliver her module to a sea of expectant faces! But in the true fashion of group work, the plan set for the group quickly evaporated when the lecture series began and the observational role of two service users developed into something more active and participative. It became a group in which all the players, that is, service users, students, and lecturer, forged a common purpose that brought a change to the planned lecture-style format and led instead to a group endeavor of learning from and sharing with each other questions, thoughts and reflections. The planned and carefully constructed observational involvement of the service users was swiftly replaced by more spontaneous and "real" discussions between everyone in the room.

This welcome but unplanned group experience raised a new set of demands on the facilitator. According to O'Dee (1995), "groupwork is a value-laden enterprise and . . reflects . . personal and professional values" (p. 172). With reference to the facilitation of educational groups, O'Dee (1995) further pointed out the need to attend to the emotional experiences of the students that may be quite strong even though the purpose of the group 
is educational: "Some students will be inhibited by the emotional impact of these materials, and allowances need to be made with respect to those students who experience, often unexpectedly, adverse reactions" (p. 173). The implication for the lecturer, given the unexpected but entirely welcome outcome of such real-life dialogue and exchanges between the group participants, was the need for her to draw yet again on her knowledge of group work facilitation skills. The Standards (AASWG, 2010) states that the worker interventions should be "characterized by flexibility, sensitivity, and creativity" (p. 7). All of these characteristics and attributes were needed to respond to the not-so-planned developments as the group took off in an unexpected direction.

For example, issues concerning limits to disclosure surfaced very quickly. The two service users were confident in their role and purpose. Both were experienced in the promotion and dissemination of service user views, and this classroom environment provided a forum in which they could impart their knowledge to a receptive audience. However, imparting their knowledge involved personal disclosure of information concerning actual and at times uncomfortable events that they had directly experienced. The debriefing after each session, originally intended as a feedback mechanism on the lecture content, provided an opportunity for me, as the lecturer, to check in with the service users after each class. In fact, the safety net this debriefing space provided was not needed, and service users, robust and grounded, used the debriefing time mainly as originally planned for giving me feedback on module content. Sometimes this included extensive guidance on issues missed by me in my presentations that they thought students should be informed about. This level of detailed feedback proved enormously informative and will be a source of extensive revision of future module content.

Such was the extent of their knowledge, that after the first couple of classes, we adjusted or loosened the lecture format, and the service users moved more center stage in classroom interactions. Sometimes the service users directly offered additional information alongside the lecturer's input. Over time, the students asked questions directly of the service users, and during breaks and after class students often approached the service users to further discuss issues that had come up in class. This afforded the students the benefit of hearing the service users' views on issues and what service users wanted to see prioritized in terms of service provision. The class discussions were wide ranging and included discussion on how service users perceived the experience of involuntary and assisted admissions, the importance of professionals offering hope to service users by providing access to a range of service models including the recovery model, the assessment of capacity and the issues that arise when a diagnosis of incapacity is made, the denial of liberty that may accompany hospitalization, and the side effects of medication. 
As the classes moved toward increased participation levels so too was there a need for the group-work skills employed by the lecturer to evolve and change. In this group encounter, students were exposed through observation to many facilitator-led values, skills, and techniques that can be used to ensure safety, respect, and confidentiality in a group. These skills and their allied values permeate the Standards (AASWG, 2010), such as "respect for persons and their autonomy" and the "creation of a socially just society through the practice of equality and the valuing of diversity in all its dimensions" (p. 4). The relevance of these skills and values was transmitted to students through the process of the group and also through the actual event of the group itself, that is, the creation of a human space in which members from different backgrounds, wearing different hats, could listen and learn from each other.

\section{STUDENT FEEDBACK}

The student feedback illuminated how the project had changed students' awareness of service user perspectives, how it had expanded their understanding of mental health problems, and how their conceptualization of mental health social work had changed. This feedback also offers some degree of insight into the impact of the group on students' awareness of and appreciation of service user expertise. Overall, the feedback was positive. Students reported that they had found it beneficial to acquire such proximate exposure to the service user viewpoint. Some of the students made connections between this increased awareness and how this would bring a different perspective to their work. The distinction between medical and social models of mental health, which often features strongly within the service user discourse, became clearer to some students who reported that their knowledge was enhanced on this issue. Students reported greater insight and awareness of the problems faced by mental health service users in getting what they need from services. Some students also reported a raised understanding of the positive use which service user feedback could bring to their work. Of particular interest was the report from one student who stated that the knowledge they had gained from the module would increase their confidence to practice within mental health services.

Some were left feeling a little confused about the role of the mental health social worker. The challenge that some service user perspectives pose to the traditional medical model of mental health proved unsettling for some students, and they struggled to reconcile the material covered in the classroom with their placement experiences in traditional mental health service settings. On the other hand, some students reported the critique of the various models of mental health and illness to be informative and helpful. One student reported increased awareness of the frustration suffered by those 
who are not listened to in society and how this is compounded when services are inadequately resourced to meet the service user's requirements. Finally, it was clear from the feedback provided by students that the exposure they gained to the views of service users enhanced their awareness of the need to consult and listen to service users and involved them centrally in the compilation of their care plan.

Feedback was not gathered from the students regarding how they believed the module improved their knowledge of group work or group facilitation. This is an issue that could be usefully included in feedback from students involved in modules such as this in the future. However, based on the feedback received from students, it is clear that the format supported student engagement with the module content. Adjectives that appeared in the student feedback forms included informative, helpful, relevant, interesting, fascinating, beneficial, and great!

\section{CONCLUSIONS}

At its conceptual stage, it was envisaged that the involvement of service users as auditors in a Social Work and Mental Health module would achieve the synchronization of the classroom and the external world of practice, so vital for students' critical-thinking skill development (Deal \& Pitman, 2009). Through this service user/educator collaboration, it was hoped that the feedback from the service users to the lecturer would inform her future teaching so that she could produce in the following academic year a better informed module and one that would provide greater insight for future students into the world of the service user.

What transpired was all of that and much more. The presence of students, service users, and lecturer together in a room created the opportunity for sharing and dialogue. The facilitation of this mixed group of participants was influenced strongly by the principles, knowledge, and values laid down in the Standards (AASWG, 2010). The educational group achieved many of its initial aims, and the feedback from students indicates that much was gained by them from the overall experience.

In reporting the experience of teaching this module, it is hoped this article stretches the conceptual limits of service user involvement in professional education, loosens the perceived ideas about how service user input to professional formation can be shaped, and throws open to debate the values that best inform the facilitation of service user/student interactions within professional education programs. It may also stimulate thought about how best to maximize the potential for developing students' skills, knowledge, and awareness by using the classroom context as a group learning experience. 


\section{NOTES}

1. The term service user is used in this article to denote those who use services. It is acknowledged that other terms exist which are used to describe people who use or receive services such as client, consumer, or sometimes in medical settings patient. It is also acknowledged that all of these terms, including service user, are problematic, albeit in different ways, because they link the service users' identity to their usage of a particular service and fail to capture the multiple dimensions of peoples' identities (McLaughlin, 2009). The terms client, customer, and consumer can imply a level of choice on the part of the person receiving services, but in mental health contexts this is not always the case as mandated treatment is possible in many jurisdictions and sometimes those receiving services have no choice in the matter. The term service user is used here as a term that describes anyone who receives a service, whether that person wishes to do so or not, and as such, it acknowledges the power differential that can sometimes exist between those who use and those who provide services.

2. An expert-by-experience in this text refers to anyone who has firsthand knowledge of a phenomenon, such as usage of health or social services (Beresford, 2007; Preston-Shoot, 2007). Beresford and Evans (1999) suggested that with the broadened base of social research, which now includes varied forms of research such as "participatory," "collaborative," and "emancipatory" inquiry, has come a greater appreciation of the contribution to knowledge that can be found through investigation of people's personal experience(s).

\section{REFERENCES}

Adams, R., Dominelli, L., \& Payne, M. (Eds.). (2005). Social work futures: Crossing boundaries, transforming practice. Basingstoke, UK: Palgrave Macmillan.

Agnew, A., \& Duffy, J. (2010). Innovative approaches to involving service users in palliative care social work education. Social Work Education: The International Journal, 29(7), 744-759.

Association for the Advancement of Social Work with Groups. (2010). Standards for social work practice with groups ( $2^{\text {nd }}$ ed.). Alexandria, VA: Author.

Beresford, P. (2007). The role of service user research in generating knowledgebased health and social care: From conflict to contribution. Evidence \& Policy, 3(3), 329-341.

Beresford, P., \& Evans, C. (1999). Research note: Research and empowerment. British Journal of Social Work, 29(4), 671-677.

Braye, S. (2000). Participation and involvement in social care: An overview. In H. Kemshall \& R. Littlechild (Eds.), User involvement and participation in social care: Research Informing Practice (pp. 9-28). Philadelphia, PA: Jessica Kingsley Publishers.

Chamberlin, J. (2005). User/consumer involvement in mental health service delivery. Epidemiologia e Psichiatria Sociale, 14(1), 10-14.

CORU (2011). Criteria and standards of proficiency for education and training programmes. Dublin, Ireland: CORU, The Health and Social Care Professionals Council.

Crossley, N. (2006). Contesting psychiatry: Social movements in mental health. London, UK: Routledge.

Cuming, H., \& Wilkins, J. (2000). Involving service users in the assessment of students in professional practice. Journal of Practice Teaching in Social Work and Health, 22(3), 17-30. 
Deal, K. H., \& Pittman, J. (2009), Examining predictors of social work students' critical thinking skills. Advances in Social Work Practice, 10(1), 87-102.

Department of Health. (2002). Requirements for social work training. London, UK: Author.

Department of Health and Children. (2006). A vision for change. Report of the expert group on mental health policy. Dublin, Ireland: Author.

Department of Health and Children. (2008). National strategy of service user involvement in the Irish health service 2008- 2013. Dublin, Ireland: Author.

Doel, M., \& Sawdon, C. (1995). A strategy for groupwork education and training in a social work agency. Groupwork, 8(2), 189-204.

Duffy, J. (2006). Participating and learning: Citizen involvement in social work education in the Northern Ireland context. London, UK: Social Care Institute for Excellence.

Duffy, J. (2008). Looking out from the middle: User involvement in health and social care in Northern Ireland. London, UK: Social Care Institute for Excellence. Retrieved from www.scie.org.uk/publications/reports/report18.pdf

Elliott, T., Frazer, T., Garrard, D., Hickinbotham, J., Horton, V., Mann, J., Soper, S., ... Whiteford, A. (2005). Practice learning and assessment on BSc (Hons) social work: Service year conversations. Social Work Education, 24(4), 451-466.

Farrell, A. (2010, Summer). Social work with young people: The benefits of being more centrally informed by the views and experiences of service users. Irish Social Worker, 20-22.

Forrest, S., Risk, I., Masters, H., \& Brown, N. (2000). Mental health service user involvement in nurse education: Exploring the issues. Journal of Psychiatric and Mental Health Nursing, 7, 51-57.

Gee, M., \& McPhail, M. (2010). The voice of service users and carers in universities. In M. McPhail (Ed.), Service user and carer involvement: Beyond good intentions (pp. 23-39. Edinburgh, Scotland: Dunedin Academic Press.

International Association of Schools of Social Work and the International Federation of Social Workers. (2004). Global standards for the education and training of the social work profession. Bern, Switzerland: International Federation of Social Workers. Retrieved from http://cdn.ifsw.org/assets/ifsw_65044-3.pdf

Jackson, C. (2005). Rhetoric and reality: Comparing practice and policy for older people and adults of working age in mental health services: Implications for social work in the field of service-user involvement. Social Care: Papers for Practice. Coventry, UK: University of Warwick, Social Care Association.

Kjellberg, G., \& French, R. (2011.) A new pedagogical approach for integrating social work students and service users. Social Work Education: The International Journal, 30(8), 948-963.

Lasalvia, A., \& Ruggeri, M. (2007). Assessing the outcome of community-based psychiatric care: Building a feedback loop from 'real world' health services research into clinical practice. Acta Psychiatrica Scandinavica, 16(Suppl s437), 6-16.

Le Riche, P., \& Taylor, I. (2008). The learning, teaching and assessment of partnership work in social work education. London, UK: Social Care Institute for Excellence.

McLaughlin, H. (2009). What's in a name: 'Client', 'patient', 'customer', 'consumer', 'expert by experience', 'service user' - What's next? British Journal of Social Work, 39(5), 1101-1117. 
O'Dee, M. (1995). Using groupwork methods in social work education. Groupwork, $8(2), 166-176$.

Oliver, M. (1990). The politics of disablement. Basingstoke, UK: Macmillan.

Preston-Shoot, M. (2007). Whose lives and whose learning? Whose narratives and whose writing? Taking the next research and literature steps with experts by experience. Evidence \& Policy, 3(3), 343-359.

Smith, M. (1995). Developing critical conversations about practice. Groupwork, 8(2), 134-151.

Tickle, A., \& Davison, C. (2008). Sowing the seeds of change: Trainee clinical psychologists' experiences of service user and carer involvement on placement. Journal of Mental Health Training, Education and Practice, 3(1), 33-41.

Warren, J. (2007). Service user and carer participation in social work. Exeter, UK: Learning Matters Ltd.

Wilson, G., \& Daly, M. (2007). Shaping the future of mental health policy and legislation in Northern Ireland: The impact of service user and professional social work discourses. British Journal of Social Work, 37, 423-439.

Wilson, G., \& Kirwan, G. (2007). Mental health social work in Northern Ireland and the Republic of Ireland: Challenges and opportunities for developing practice. European Journal of Social Work, 10(2), 175-191. 